\title{
Book Review: Goldstein, B. E. 2012. Collaborative Resilience: Moving Through Crisis to Opportunity. The MIT Press, Cambridge, Massachusetts
}

\author{
Lisen Schultz $^{1}$
}

In the Anthropocene, an epoch where human activities change biophysical processes on a planetary scale, we urgently need to understand how to tip our societies towards sustainability (Westley et al. 2011). It is often claimed, that if navigated correctly, crisis can provide an opportunity for such a tip. But why is it that some crises bring people together and mark the beginning of a positive transformation, while others ignite blame games and desperate efforts to maintain status quo? How does collaboration shape the way we cope with, adapt to, and transform through crises? And what can we do, as scientists, natural resource managers, and planners, to support our societies' capacity to respond to crises in a constructive way?

Goldstein (2012) has gathered a diverse group of scholars from the fields of planning and natural resource management to explore these questions in depth. In both fields, failures of overly confident managerial approaches have sparked an increasing interest in multi-stakeholder collaboration, learning, and flexibility. In his book, Collaborative resilience: Moving Through Crisis to Opportunity, the reader is presented with rich case studies of these new approaches as well as clear and innovative syntheses of lessons learned. As Goldstein points out in the introduction, "you will not learn from this book any specific guidelines for practice". Instead, "you will come away with situated knowledge, contingencies, details, analogies, and interpretations". The result is a set of stories that aim to inspire scholars and practitioners to contribute to a just social-ecological resilience.

The book begins with five chapters on the ways that collaborative processes contribute to resilience. Ozawa discusses the importance and fragility of trust, drawing on case studies of a nuclear accident and a contested policy response to terrorism. Zellner, Hoch, and Welch show how the complexity of social-ecological systems can inhibit trust to develop, and argue that collaboration can help actors to recognize their interdependence and foster solidarity. Kaufman addresses collaborative planning as a means to enhance cognitive capacity and compensate for the limited ability of individuals to understand and respond to socialecological complexity. Carp emphasizes that collaborative processes are inherently slow and illuminate the qualities that slowness brings, using the Slow food and Slow city movements as examples. Randolph ends with a synthesis approach for building climate resilient communities, where social mobilization is combined with expert practice.

The eight case studies in the second part of the book are pedagogically divided in two sections. "Reaching consensus" presents cases that analyze the role of collaboration in adaptation, i.e., the process of maintaining system continuity and integrity under changing conditions. Bojórquez-Tapia and Eakin give a detailed and nuanced account of the processes and outcomes of a participatory mapping of land suitabilities on a Mexican island. Weber gives an interesting story of how a collaborative initiative united a deeply divided community in the US. McConney and Phillips report on their action research in the Caribbean, where they assisted and analyzed the development of a network for fisherfolk organizations for improved governance of small-scale fisheries. Dukes, Williams, and Kelban examine several cases where people have suffered "unrightable wrongs", such as slavery, and the ways that communities may overcome the deep division and distrust that such trauma can cause. "Advocating change" presents cases that analyze the role of collaboration in transformation, i.e., the process of creating a new system when the current one is untenable. As Goldstein observes in the introduction, while collaboration for adaptation is highly inclusive, collaboration for transformation seems to require that certain stakeholders be excluded. For example, Arthur, Friend, and Marschke urge adaptive comanagement scholars to prioritize the aspirations of marginalized groups and support their efforts to challenge status quo, rather than trying to reduce conflict and foster collaboration. Based on their experiences of adaptive comanagement in the Mekong fisheries, they warn that the latter approach may only perpetuate inequities. Along the same lines, Till suggests that urban resilience relies on the capacity to challenge dominant understandings, and describes how a museum in South Africa contributes to this through providing space for "place-based memory-work" by previously excluded groups. Bullock, Armitage, and Mitchell describe how disempowered actors formed a shadow network that was able to address the long-term decline in forest health and economy in Northern Ontario, Canada. Finally, Butler and Goldstein tell the story of the US Fire Learning Network, which linked place-based multistakeholder collaboratives in

\footnotetext{
${ }^{1}$ Stockholm Resilience Centre and Department of Systems Ecology, Stockholm University
} 
a larger network at regional and national scales, with the aim of transforming practices around forest fire. They suggest that this type of network generates a social imaginary, a new common sense, which can catalyze a social cascade from within.

In the concluding chapter, Goldstein reflects on the complementarities and productive tensions between resilience scholars and planning scholars and suggests that "communicative resilience" - a new field of inquiry and practice - emerges from their interaction. Resilience thinking encourages planners to integrate social and ecological concerns, and to build capacity for adaptation and transformation, rather than aiming to bounce back from immediate crises. Resilience scholars, on the other hand, are challenged to "leave positivism behind" and embrace the search for meaning rather than testing falsifiable hypotheses. Goldstein argues that collaboration goes beyond joint factfinding and social mobilization for understanding and managing a social-ecological system. In the collaborative process the system itself is defined, and reshaped. "Communicative resilience" is therefore both a process and an outcome of collective engagement with social-ecological complexity.

As a social-ecological resilience scholar with a background in systems ecology, I should be a decent representative of the group that Goldstein asks to leave positivism behind. However, I do not feel targeted. It is obvious to me, and also to the many colleagues I have discussed this with, that pure positivism has little to offer if we want to understand socialecological systems that are inherently uncertain, complex, and shaped by mental models. Perhaps, we are closer to communicative resilience than we might think? With this said, I really appreciate the respectful yet clear language that carries through the whole volume. While no chapter seems to be forced into a certain structure, the stories still come naturally after one another, each spurring new insights that eventually build up to a whole. Goldstein and his co-authors have managed to produce an edited book that is much more than the sum of its chapters, and where multiple perspectives are allowed to co-exist and contribute to a new field of inquiry. The book is an excellent and unique contribution to the field of social-ecological resilience that should be of interest for broad audiences of researchers and practitioners, in natural resource management as well as planning. I hope that it will be read and discussed widely. In the Anthropocene, stories of deliberate, ethical, and resilient transformations, as well as discussions about what such transformations involve, are needed more than ever.

\section{BOOK INFORMATION}

Goldstein, Bruce Evan. 2012. Collaborative Resilience: Moving Through Crisis to Opportunity. The MIT Press, Cambridge, Massachusetts. 424 pp., hardcover \$54.00 ISBN 978-0-262-01653-7, paperback \$27.00, ISBN 978-0-262-51645-7.

Responses to this article can be read online at: http://www.ecologyandsociety.org/issues/responses. $\mathrm{php} / 5189$

\section{LITERATURE CITED}

Westley, F., P. Olsson, C. Folke, T. Homer-Dixon, H. Vredenburg, D. Loorbach, J. Thompson, M. Nilsson, E. Lambin, J. Sendzimir, B. Banarjee, V. Galaz, and S. van der Leeuw. 2011. Tipping towards sustainability: emerging pathways of transformation. Ambio 40:762-780. http://dx.doi. org/10.1007/s13280-011-0186-9 